\title{
Overnight Titration of Human Respiratory Syncytial Virus Using Quantitative Shell Vial Amplification
}

BioTechniques 25:644-647(October 1998)

\author{
Joseph B. Domachowske and \\ Cynthia A. Bonville \\ State University of New York \\ Health Science Center at Syra- \\ cuse, Syracuse, NY, USA
}

The ability to reliably titrate human respiratory syncytial virus (RSV) is important in the development and evaluation of new antiviral drugs and for the facile manipulation of this virus in clinical and basic research endeavors. Since the isolation of human RSV by Chanock et al. in 1957 (3), investigators have relied on endpoint dilution or conventional plaque assay methods for its titration. The latter is considered to be more accurate (10). In RSV plaque assays, plaques that can be macroscopically counted in 9 days under agar overlays (7) or in 13 days under a liquid overlay (8) give reliable and reproducible titrations of a stock aliquot of virus. More rapid systems have also been described, in which syncytia or plaques can be microscopically enumerated in tissue culture or under a semi-fluid overlay of methylcellulose (4) in as few as 3 days. A microassay using a 3-7-day incubation period has also been described (10). We report the development of a simple and rapid titration assay for RSV using a quantitative shell vial approach. This assay is easy to perform, and the titration results are available in $16 \mathrm{~h}$.

To prepare the viral stocks, RSV type B (RSV-B), of the family Para- myxoviridae (ATCC VR-1401), and HEp-2 laryngeal carcinoma cells were obtained from ATCC (Rockville, MD, USA). HEp-2 cells were maintained in RPMI 1640 Medium (Life Technologies, Gaithersburg, MD, USA) supplemented with $10 \%$ heat-inactivated fetal bovine serum (FBS), $2 \mathrm{mM}$ glutamine and antibiotics (c-RPMI). RSV-B was used to inoculate $180-\mathrm{cm}^{2}$ flasks containing semi-confluent (ca. 60\%) monolayers of HEp-2 cells in $50 \mathrm{~mL}$ media. When cytopathic effect, determined by visual inspection of syncytia formation, reached approximately $80 \%$, the supernatants were harvested by centrifugation at $800 \times g$ to pellet cellular debris, then flash-frozen in 1$\mathrm{mL}$ aliquots and stored at $-80^{\circ} \mathrm{C}$. Six different stock RSV aliquots were used for the experiments described.

The shell vial titration assay uses 1dram shell vials containing round coverslips with confluent monolayers of HEp-2 cells (Viromed, Minneapolis, MN, USA). Monolayers were inspected for confluency before use. Serial twofold dilutions of the virus stock were prepared in c-RPMI (1:50 to 1:3200). Shell vials were inoculated with $200 \mu \mathrm{L}$ of virus from each dilution, then centrifuged at $700 \times g$ at $22^{\circ} \mathrm{C}$ for $1 \mathrm{~h}$. Aliquots of the same dilution were used in standard plaque assays (described below). One milliliter of maintenance medium was added, and the shell vials were incubated at $37^{\circ} \mathrm{C}$ for $16 \mathrm{~h}$ and then fixed with acetone for $20 \mathrm{~min}$. Immunofluorescence staining was performed by 60 -min incubations of mouse anti-RSV fluorescein isothiocyanate (FITC)-labeled monoclonal antibody
(CHEMICON International, Temecula, CA, USA). Stained coverslips were mounted onto slides with FA Mounting Fluid, pH 7.2 (Difco Laboratories, Detroit, MI, USA). Each coverslip was observed using fluorescence microscopy at $200 \times$ magnification, and the number of fluorescent cells per coverslip was determined. Each dilution was performed in triplicate.

The RSV plaque titration assay is a standard plaque assay that was performed on the same RSV dilutions that were used to inoculate the shell vials. Each plaque assay was matched to a shell vial and inoculated with the same dilution of RSV. The assay was performed as described by Kisch and Johnson in 1963 (7). Briefly, HEp-2 cells seeded at $4 \times 10^{5}$ cells $/ \mathrm{mL}$ in 6 well tissue culture plates were allowed to grow for $48 \mathrm{~h}$. The medium was removed, and $1 \mathrm{~mL}$ of the appropriate RSV dilution (twofold serial dilutions in c-RPMI from 1:50 to 1:3200) was added to the cell monolayer. The virus was allowed to adsorb for $1 \mathrm{~h}$ at $37^{\circ} \mathrm{C}$, and the plates were tilted every $15 \mathrm{~min}$ to distribute the inoculum evenly over the surface. Three milliliters of $0.75 \%$ overlay medium (1.5\% molten agarose added to an equal volume of prewarmed c-RPMI) were added to each well and swirled gently to mix. Plates were incubated at $37^{\circ} \mathrm{C}$ in $5 \% \mathrm{CO}_{2}$ for 4 days, at which time a second $(0.5 \%)$ overlay medium was added. Incubation was continued for 4 more days, then the cell monolayers were fixed in $10 \%$ formaldehyde, and the agarose plugs were removed and stained for $5 \mathrm{~min}$ with $0.03 \%$ aqueous methylene blue. 
Table 1. Comparison of Viral Dilution with Plaque Assay Titration and Shell Vial Titration

\begin{tabular}{|lcc|}
\hline $\begin{array}{l}\text { Virus } \\
\text { Dilution }\end{array}$ & $\begin{array}{c}\text { Plaque Assay Titration } \\
\text { (number of plaques } \times \text { dilution) } \\
\text { pfu/mL }\end{array}$ & $\begin{array}{c}\text { Shell Vial Titration } \\
\text { (immunofluorescent foci } \times \text { dilution } \times 5) \\
\text { immunofluo rescent foci/mL }\end{array}$ \\
\hline $1: 200$ & 799200 & 868000 \\
$1: 400$ & 873200 & 924000 \\
$1: 800$ & 801600 & 784000 \\
$1: 1600$ & 830000 & 838000 \\
$1: 3200$ & 798400 & 796000 \\
NOTE: Representative experiment using single matched pairs at each dilution. \\
\hline
\end{tabular}

The wells were allowed to dry completely after removing the stain, and plaques were counted with the aid of a dissecting microscope. All dilutions were performed in triplicate.

Statistical analyses included Pearson correlations and paired $t$ tests. Bland-Altman plots and $95 \%$ limits of agreement were used to determine the practical utility of shell vial titration $(1,2)$. A $P<0.05$ was considered statistically significant.

Fifty matched plaque assay/shell vial pairs were available from 6 different RSV stocks diluted 1:200 to 1:3200. More concentrated RSV dilutions led to plaques too numerous to count, although the shell vial counterparts could

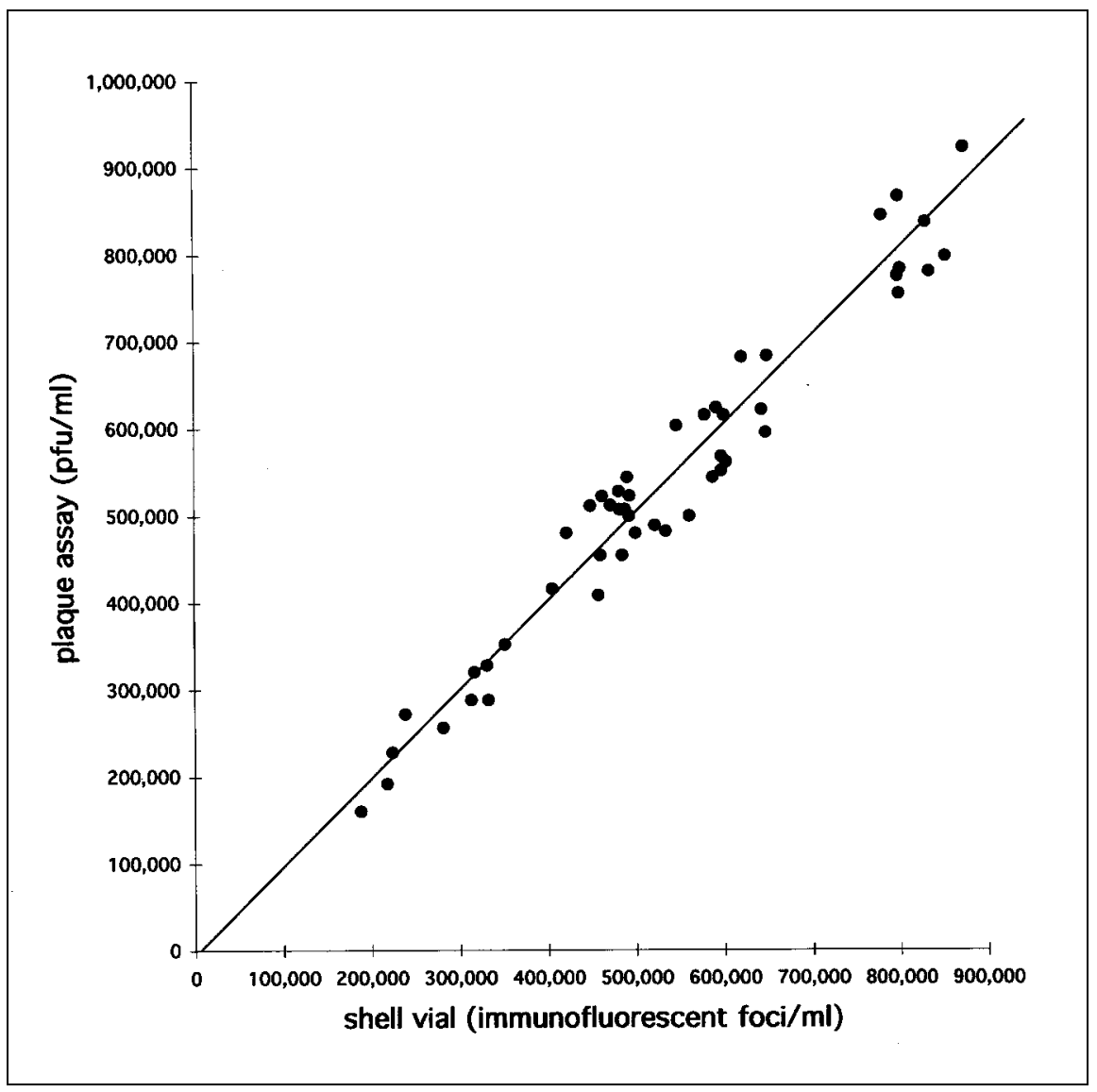

Figure 1. Line of unity and a bivariate scattergram of plaque assay pfu/mL vs. shell vial immunofluorescent foci/mL of virus dilution from the 50 available matched pairs. $r^{2}=0.997$. 


\section{Diagnostic Techniques}

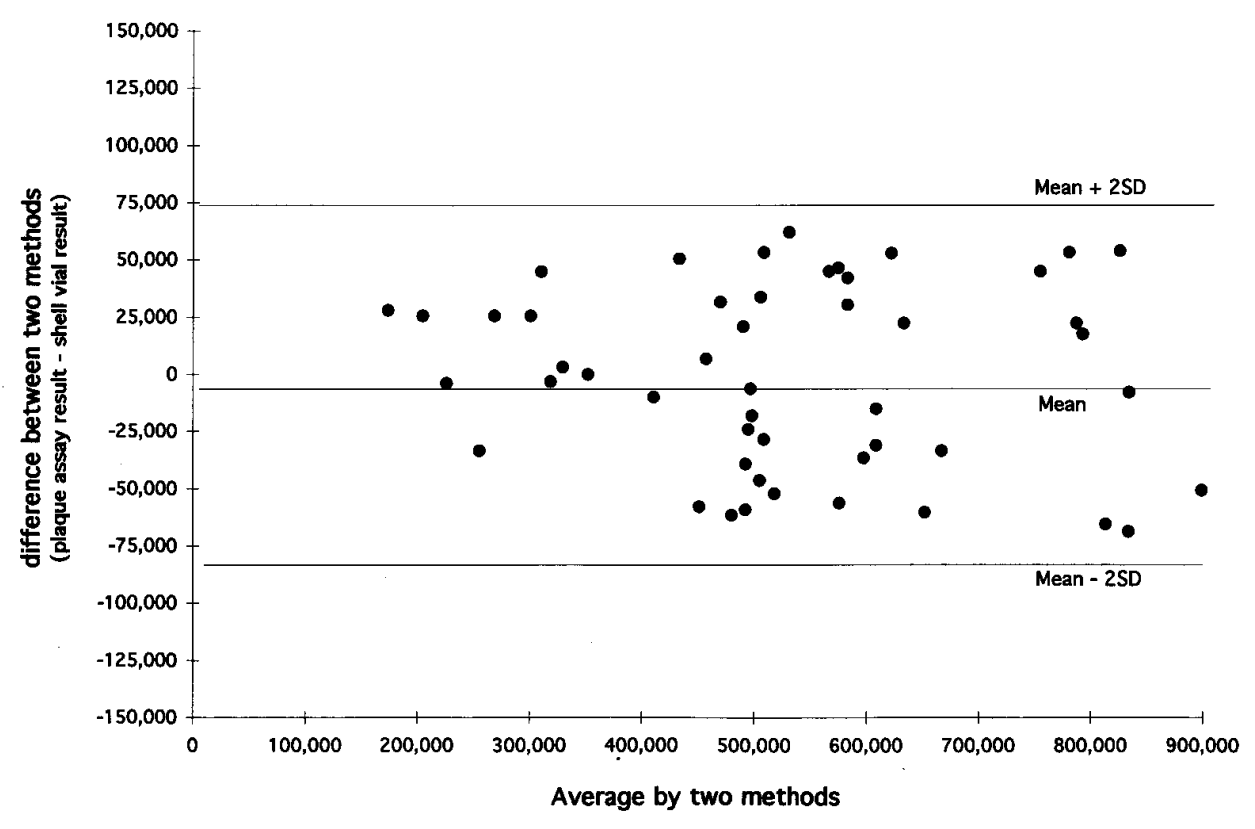

Figure 2. Bland-Altman plot of plaque assay and shell vial data. Mean difference between plaque assay pfu/mL and shell vial immunofluorescent foci/mL as well as $95 \%$ limits of agreement are shown. 
still be enumerated. Table 1 shows a representative experiment comparing plaque assay titration with shell vial titration at stock RSV dilutions from 1:200 to 1:3200. At virus dilutions less than 1:200, we suspect that actual plaques might be coalescing resulting in falsely low-titer results. Figure 1 shows the line of unity and a bivariate scattergram of plaque assay plaque-forming units (pfu)/mL vs. shell vial immunofluorescent foci $/ \mathrm{mL}$ of virus dilution from the 50 available matched pairs. Figure 2 shows a Bland-Altman plot of this data. Mean difference between plaque assay $\mathrm{pfu} / \mathrm{mL}$ and shell vial immunofluorescent foci $/ \mathrm{mL}$ as well as 95\% limits of agreement are shown.

The plaque assay $\mathrm{pfu} / \mathrm{mL}$ and the shell vial immunofluorescent foci/mL were highly correlated $\left(r^{2}=0.977\right)$. The relative average bias of the shell vial results was -76 , with shell vial results higher than plaque assay results and $95 \%$ limits of agreement of +79 832 and -79984 . The absolute value of the difference between plaque assay and shell vial results was never $>65000$ (Figure 2).

These data demonstrate that the simple, rapid shell vial amplification assay can be used to reliably titrate human RSV. The development of this assay system has facilitated our evaluation of the antiviral properties of eosinophilderived ribonucleases (5) and can be used to evaluate the efficacy of other novel antiviral agents. Moreover, this quantitative shell vial technique can also be developed for use in titration of human cytomegalovirus (6), influenza $A$, influenza $B$ and parainfluenza viruses 1, 2 and 3 (unpublished observations). Compressing the required incubation period for virus detection is standard in clinical virology laboratories. While immunofluorescence has been used to assay RSV infectivity (9), this description predates the advent of shell vial technology and demonstrated that RSV adsorption time (to the target cell monolayer) was $3 \mathrm{~h}$ or more. Shell vial spin amplification reduces this time to $1 \mathrm{~h}$ or less. Moreover, no direct comparison with traditional plaque assays was included in that report. The observation that this technique can be used in a quantitative fashion provides a new tool for virus titration.

\section{ACKNOWLEDGMENTS}

We thank Drs. Helene Rosenberg and Len Weiner for their insightful discussions. We thank Dr. Marc Harrison for help with the statistical analysis. This work was funded by The Children's Miracle Network.

\section{REFERENCES}

1.Bland, J.M. and D.G. Altman. 1995. Comparing methods of measurement: why plotting difference against standard method is misleading. Lancet 346:1085-1087.

2.Bland, J.M. and D.G. Altman. 1986. Statistical methods for assessing agreement between two methods of clinical measurement. Lancet 1:307-310.

3.Chanock, R.M. and L. Finberg. 1957. Recovery from infants with respiratory illness of a virus related to chimpanzee coryza agent (CCA). II. Epidemiologic aspects of infection in infants and young children. Am. J. Hyg. 66:291-300.

4.Coates, H.V., D.W. Ailling and R.M. Chanock. 1966. An antigenic analysis of respiratory syncytial virus isolates by a plaque reduction test. Am. J. Epidemiol. 83:299-313.

5.Domachowske, J.B., K.D. Dyer, C.A. Bonville and H.F. Rosenberg. 1998. Recombinant human eosinophil-derived neurotoxin/RNase 2 functions as an effective antiviral agent against respiratory syncytial virus. J. Infect. Dis. 177:1458-1464.

6.Forbes, B.A., C.A. Bonville and N. Dock. 1990. The effects of a promoter of cell differentiation and selected hormones on human cytomegalovirus infection using an in vitro cell system. J. Infect. Dis. 162:39-45.

7.Kisch, A.L. and K.M. Johnson. 1963. A plaque assay for respiratory syncytial virus. Proc. Soc. Exp. Biol. Med. 112:583-589.

8.Loh, P.C., B.C. Achong and M.A. Epstein. 1977. Further biological properties of the human syncytial virus. Intervirology 8:204-217.

9.Schieble, J.H., A. Kase and E.H. Lennette. 1967. Fluorescent cell counting as an assay method for respiratory syncytial virus. J. Virol. 1:494-499.

10.Trépanier, P., P. Payment and M. Trudel. 1980. A simple and rapid microassay for the titration of human respiratory syncytial virus. J. Virol. Methods 1:343-347.

Received 24 March 1998; accepted 27 April 1998.

Address correspondence to:

Dr. Joseph B. Domachowske

SUNY HSC at Syracuse

Department of Pediatrics

750 East Adams Street

Syracuse, NY 13210, USA

Internet:domachoj@vax.cs.hscsyr.edu 